\title{
Practical Experiences for the Development of Educational Systems in the Semantic Web
}

\author{
$M^{a}$ del Mar Sánchez Vera ${ }^{1, *}$, Jesualdo Tomás Fernández Breis ${ }^{2}$ José Luis Serrano \\ Sánchez ${ }^{3}, M^{a}$. Paz Prendes Espinosa ${ }^{4}$ \\ 1Dpto. Didáctica y Organización Escolar, Universidad de Murcia, Spain \{mmarsanchez@um.es\} \\ ²Dpto. Didáctica y Organización Escolar, Universidad de Murcia, Spain \{jfernand@um.es\} \\ ${ }^{3}$ Dpto. Didáctica y Organización Escolar, Universidad de Murcia, Spain \{jl.serranosanchez@um.es\} \\ ${ }^{4}$ Dpto. Didáctica y Organización Escolar, Universidad de Murcia, Spain \{pazprend@um.es\} \\ Received on 18 October 2012; revised on 29 October 2012; accepted on 3 December 2012; published on 15 January 2013 \\ DOI: 10.7821/naer.2.1.23-31
}

\begin{abstract}
Semantic Web technologies have been applied in educational settings for different purposes in recent years, with the type of application being mainly defined by the way in which knowledge is represented and exploited. The basic technology for knowledge representation in Semantic Web settings is the ontology, which represents a common, shareable and reusable view of a particular application domain. Ontologies can support different activities in educational settings such as organizing course contents, classifying learning objects or assessing learning levels. Consequently, ontologies can become a very useful tool from a pedagogical perspective. This paper focuses on two different experiences where Semantic Web technologies are used in educational settings, the difference between them lying in how knowledge is obtained and represented. On the one hand, the OeLE platform uses ontologies as a support for assessment processes. Such ontologies have to be designed and implemented in semantic languages apt to be used by OeLE. On the other hand, the ENSEMBLE project pursues the development of semantic web applications by creating specific knowledge representations drawn from user needs. Our paper is consequently going to offer an in-depth analysis of the role played by ontologies, showing how they can be used in different ways drawing a comparison between model patterns and examining the ways in which they can complement each other as well as their practical implications
\end{abstract}

KEYWORDS: LEARNING, ASSESSMENT, EDUCATIONAL TECHNOLOGY, ONLINE SYSTEMS, INTERNET

\section{INTRODUCTION: ONTOLOGIES AND THE SEMANTIC WEB IN ELEARNING}

The Semantic Web aims to add semantic information to web contents in order to create an environment where software

\footnotetext{
${ }^{*}$ To whom correspondence should be addressed: Universidad de Murcia

Facultad de Educación, Campus de Espinardo

Departamento de Didáctica y Organización Escolar 30100 Murcia

Spain
}

agents can perform tasks efficiently (Berners \& Hendler, 2001). The Semantic Web proposes the idea that web contents are defined and linked not only for visualization but also to be used by applications. That is why the Semantic Web represents a promising technology to implement e-learning systems. Furthermore, Stojanovic, Staab, and Studer (2001) showed that the Semantic Web meets the basic e-learning requirements, namely: speed, just-in-time and pertinent learning. The appropriateness of Semantic Web technologies for developing eLearning systems is also supported by the research work undertaken in the last years from different perspectives (see Fensel, Staab, Studer, Van, \& Davies, 2003; Devedzic, 2006; Bittencourt, Costa, \& Silva, 2009; amongst others).

The Semantic Web has as its aim to go beyond the limits of the current web by introducing explicit descriptions of meaning, the internal structure and the overall structure of the contents and services available on the WWW. Before the chaotic growth in resources and the absence of any clear organization in the web today, it advocates a classification, structuring and annotation of resources with explicitations that can be processed by semantic machine.

A number of technologies are needed for the success of the Semantic Web. The Semantic Web stack includes languages and standards ranging from how characters are represented to how security can be guaranteed. However, ontologies have become the cornerstone of the technology required if all the information is to be made understandable by machines. A large number of definitions for ontology can be found in the literature (see Gruber, 1993 or Van Heist, Schereiber, \& Wielinga, 1997, for instance). Ontologies define common, shareable and reusable views of a domain, giving meaning to information structures that are exchanged by information systems (Brewster \& O'Hara, 2007). Ontology can be seen as a semantic model that contains concepts, their properties, interconceptual relationships, and axioms related to the aforesaid elements. In practical settings, ontologies have become widely utilized because they are reusable and shareable (see Fernández-Breis \& Martínez-Bejar, 2002 and Brewster \& O'Hara, 2007, amongst others).

On the e-Learning side, some standards and recommendations state the need for Semantic Web-based approaches. On the one hand, the Learning Object Metadata (LOM) standard recommends the annotation and classification of learning objects, using metadata to facilitate their retrieval. On the other 
hand, The IMS LD specification, which describes the learning process that takes place in learning units, is currently described using the ontology (Amorín, Lama, Sánchez, Riera, \& Vila, 1995).

However, the development of ontologies has never been easy and getting such a degree of shared semantics in the web is a task that will take a few years. That is why Linked Data have been proposed as a way to facilitate data exchange in the Web. Linked Data permit using the Web to connect related data. According to Wikipedia, it describes a recommended best practice for exposing, sharing, and connecting data, information, and knowledge on the Semantic Web using URIs and RDF.

\section{METHODS: INFORMAL AND FORMAL REPRESENTATIONS OF DATA AND KNOWLEDGE}

This section provides more information about the nature and properties of ontologies that can turn out to be useful within learning environments; that will allow us to introduce how knowledge is used by the two research projects analysed in later sections of this paper.

The formal notion of ontology means that ontology knowledge is formal; it has a specific structure with a particular, deterministic, and inflexible meaning. This is probably a required property of ontologies in certain domains and applications, but it limits their applicability too. Our attention in this paper will also be placed in dealing with the view that consider ontologies as a way to structure information that provides more powerful tools than relational models, for instance.

\subsection{Results and discussion: Types of Ontologies}

The Semtech (Semantic Technologies for Learning and Teaching) draws a distinction between hard semantic technologies and soft semantic technologies according to their structure level. An in-depth look at this topic reveals mixed views about soft ontologies. Some authors use the term lightweight (Corcho, Fernández, \& Gómez, 2003) while others speak about soft ontologies. In any case, it seems that both terms try to unite apparently irreconcilable ontological differences through contextual analysis. Consequently, when an attempt is made to represent knowledge in a structured way, disciplines or subjects often appear that cannot be structured in a clear taxonomy. This is where soft ontologies come into play.

SemTech makes a distinction between the so-called soft and hard semantic technologies and between linked data and 'traditional' metadata using ontologies like those stated in Tiropanis et al., (2009) (the main differences between soft and hard ontologies can be seen in Figure 1):

- Soft/light semantic technologies let people document certain concepts in formats that can be easily communicated to other people as part of learning and teaching processes. Examples of soft semantic annotation include folksonomies and topic maps. These ontologies refer to a flexible ontology that organizes concepts and ideas into a comprehensive taxonomy or classification (Avilés, Diaz-Kommonen, Laipainen, \& Piertarila, 2003). Having a soft ontology does not mean less effectiveness. There are areas where it is difficult to establish clear relationships. The development of soft ontologies or lightweight ontologies allows us to work within these complicated environments and organize knowledge so that a Semantic Web tool can be created in future. Therefore, making a fixed, immovable structure of content seems to be really difficult in certain contexts. That is why soft ontologies can be very practical in areas such as teaching.

- Hard/strong semantic technologies support efficient exchange and processing of semantic data between programs and machines. An example would be linked data constructed from RDF statements. These ontologies are structured by means of specific languages such as RDF or OWL; they are usually developed through ontology editors such as Protegé.

Figure 1. Differences between soft/light ontologies and hard/strong ontologies

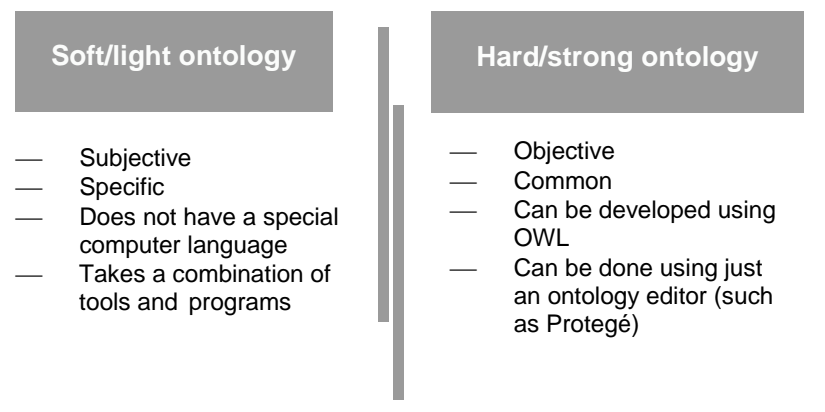

As shown above, it is very difficult to find an agreement on common vocabularies and shared conceptualizations even in restricted domains. Different agents use the same word to mean different things or use different words to mean the same thing. This is what Bouquet, Dona, Serfafini, and Zanobini (2002) call semantic heterogeneity, namely a situation in which agents do not understand each other because they use languages with heterogeneous semantics.

A local ontology cannot be exclusively seen as a disadvantage, since it allows us to work with specific environments that can play a fundamental role in education. However, this perspective needs to be considered when an effort is being made to build and organize information. It could be a tremendously useful tool, but only within a given environment, i.e. the one for which it was developed. In fact, a local ontology can be either soft or hard, as it is the contextualization of its contents and not its degree of formalization and axiomatization that determines this classification. While formal ontologies assume that their knowledge is valid in any possible world and interpretation, local ontologies are supposed to contain valid knowledge in a particular context of use -which brings them closer to application ontologies.

\section{SEMANTIC WEB TECHNOLOGIES FOR ASSESSMENT: OELE}

The assessment of students' knowledge or skills is a basic activity both in traditional education and in e-learning. This is usually done by giving students tests which can contain different types of exercises, such as open questions, closed questions, puzzles, matching games and so on. Each type of exercise tries to evaluate a different ability level of students. Bloom (1956) developed his taxonomy with six levels of intellectual behaviour: evaluation, synthesis, analysis, application, understanding and knowledge. Cognitive memory or fact 
recognition represents the lowest level, whereas the highest level corresponds to evaluation, which requires a more abstract and complex problem-solving ability. The aforementioned taxonomy permits to classify abstraction levels in the questions and exercises used to assess students' work.

Different authors agree with the statement according to which the higher levels of Bloom's taxonomy can only be evaluated through open questions (Birenbaum, Tatsouka, \& Gutvirtz, 1992; McGrath, 2003; Mitchell, Aldridge, Williamson, \& Broomhead, 2003; Palmer \& Richardson, 2003). These questions are not difficult to design for teachers, although their manual evaluation is difficult and sometimes based on superficial properties of the answer, such as the presence of important terms. In this case, students may easily cheat the assessor by writing general lines and a few senseless contents with the terms that the assessor is looking for. An appropriate evaluation process must be based on the careful reading of answers, looking for clarity and logic. Moreover, this task becomes exhausting if the evaluator has to mark a large number of exams. Nevertheless, the assessment of open questions without human participation becomes a serious issue before the need to evaluate a natural language text and requires the development of new methodologies to support such processes.

Different techniques have traditionally been applied to the assessment of open questions. In particular, knowledge representation techniques such as semantic networks or lexical conceptual structures (see Devin, 1998; Olsen, 1998; Whittingdon \& Hunt 1999, amongst others) can be found. In recent years, Topic Maps (Maicher \& Park, 2005) have been widely used for the conceptualization of domains within educational settings. Topic maps can represent information using topics, associations (which represent the relationships between them) and occurrences. They are thus similar in many aspects to semantic networks and to both concept and mind maps. However, their knowledge is not formalized and requires the definition of the topic map ontology.

Computer-assisted assessment systems for students can also be found (Friedler \& Shneiderman, 2008; Falquet \& Mottaz, 2004; Alfonseca \& Pérez, 2004). Most of them combine natural language processing and statistical techniques to deal with students' answers. Finally, our group has already used ontologies to support the assessment of individuals in group work (Fernández-Breis et al., 2007).

Feedback is obviously related to assessment, because it permits to give back to the student information which was provided by the latter student -and which has now been improved thanks to the processing carried out by the teacher. Feedback is not only an instrument that has to be utilized to improve students' learning; it must bring an improvement of the whole teaching-learning process. Collecting students' feedback is a central strategy to monitor teaching and learning quality/standards in higher education institutions.

Considering all the above, the developers of the OeLE platform found the following reasons for applying ontologies to support assessment processes:

Ontologies can provide a precise semantic specification of the domain: in this case, the knowledge which students must acquire through the course.

Semantic annotations can be used to get a precise semantic specification of questions and answers.

Automatic feedback processes can be developed by combining course ontologies and semantic annotations.

\subsection{Description of the OeLE platform}

The OeLE platform resulted from the joint work carried out by two research groups from the Computer Science and Education Faculties at the University of Murcia (Southeast Spain). This platform allows running assessment tests that go beyond the multiple-choice test traditionally used online. One of the great features that it offers is the possibility of taking concepts developed by students and using them to provide feedback about those students' performance in the test, indicating what things were done well, the errors, etc., and ultimately to provide feedback on the learning process as a whole.

Ontologies in OeLE represent the knowledge that the students have to acquire in a particular course. Course assessment of the course is done by giving students tests based on open questions. Each open question is associated with a specific set of semantic annotations, which are in turn the parts of the course ontology that students should have acquired to answer it correctly. Semantic annotations are also associated with students' answers in natural language, this being a semiautomatic part of the process where the support of natural language processing techniques plays an essential role. The mark will then be proportional to the semantic similarity between both sets of annotations.

OeLE aims to support the design and improvement of assessments tests in e-learning-type courses. This approach is based on the following assumptions which reveal the need for Semantic Web technologies to achieve our goal:

- Course knowledge can be modeled by means of ontologies, that is, using concepts, relationships and attributes. In particular, ontologies in this work are expressed through the Ontology Web Language (OWL) (Web Ontology Working Group, 2004), which acts as the "de facto" standard.

- Semantic annotations can be associated with assessment questions. Annotations will be defined for a particular question at two levels: the answer expected by the teacher and the actual answers given by students.

- Exams are evaluated using a methodology based on semantic similarity measurements. This similarity is calculated from the expected answer and the answer actually given by the student. The similarity is calculated with the semantic annotations extracted from both answers.

In OeLE the exams done by students are annotated with respect to the course ontologies and those OeLe contain modules which permit the automatic calculation of a student's mark through the comparison of annotations respectively associated with the students' answers and the expected answer -defined by the teacher. In addition to this, OeLE allows students and teachers to receive feedback information through the semantic analysis of the answers given by students in an examination. That semantic analysis is performed in the context of the course ontology. The platform permits to implement different marking policies and strategies by changing values in the set of parameters used for calculating students' marks.

Some OeLE screenshots are described next. The teacher uses the screen shown in Figure 3 to evaluate each question. This screen is divided into two halves. The left hand-side refers to the question, whereas the right hand-side refers to the answer provided by the student. The following information appears for a question: description; expected answer (optional); the semantic 
annotations making explicit what the students are expected to answer; and the marks assigned to this question. Concerning the answer, the following information is provided: the text answer; the semantic annotations derived from the text answer; and the marks given to students. Two fields are provided for this issue: manual marking (done by the teacher) and automatic marking (calculated by the system). The final mark for the exam results from combining the marks obtained in each question.

Feedback is generated in OeLE for any answer given by a student in an open question as described below and partially shown in Figure 2. The following process is executed for each semantic annotation of the student's answer. The degree of semantic similarity between one semantic annotation of the student's answer and all the annotations of the expected answer belonging to the same ontological category is obtained; this results in a table where rows are the annotations of the student's answer and columns the annotations for the expected answer. Each cell contains the semantic similarity value.

Figure 2. Marking the question

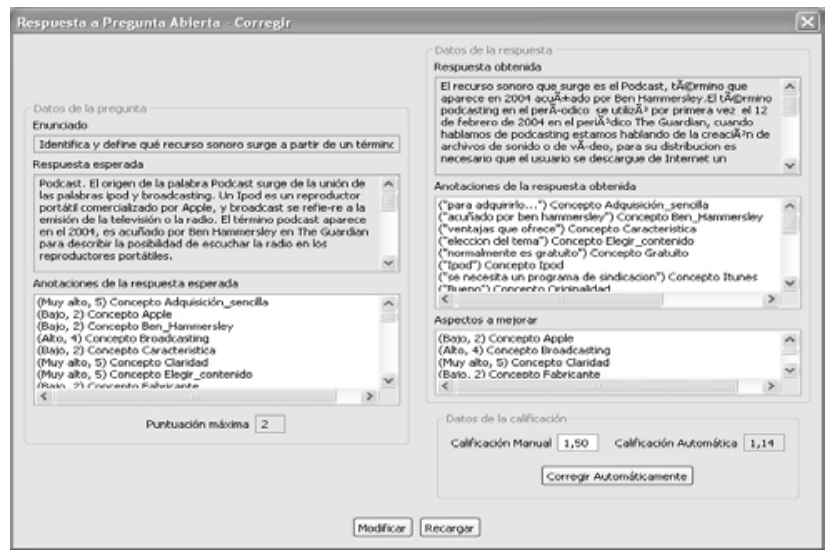

The result of this analysis is composed of two lists:

- Knowledge not acquired ("aspectos a mejorar [aspects to be improved]"): this list contains the knowledge items that were expected to be answered in this question but were not provided by the student. Figure 4 shows that the student did not give an answer for the concepts "design bases”, "design phases" and "recommendations," the relationships "design bases are the bases of pedagogical design" and also "design bases are the bases of technical design," and, finally, the attribute "main aspects of design bases."

- Knowledge contained in the answer ("Items respondidos por el alumno [Items answered by the student]"): the marking process obtains a set of semantic annotations from the student's answer. The feedback is then generated by showing the correctness of each ontological entity extracted from the student's answer. Figure 3 only shows the concept Tools ("herramientas") which was correctly answered by the student. Wrong items have a red cross next to them.

The feedback generated by the platform also allows teachers to know which aspects have been acquired best and worst by the students. Figure 4 shows how OeLE displays the analysis of students' exams graphically.
Figure 3. Excerpt of the feedback generated by the student

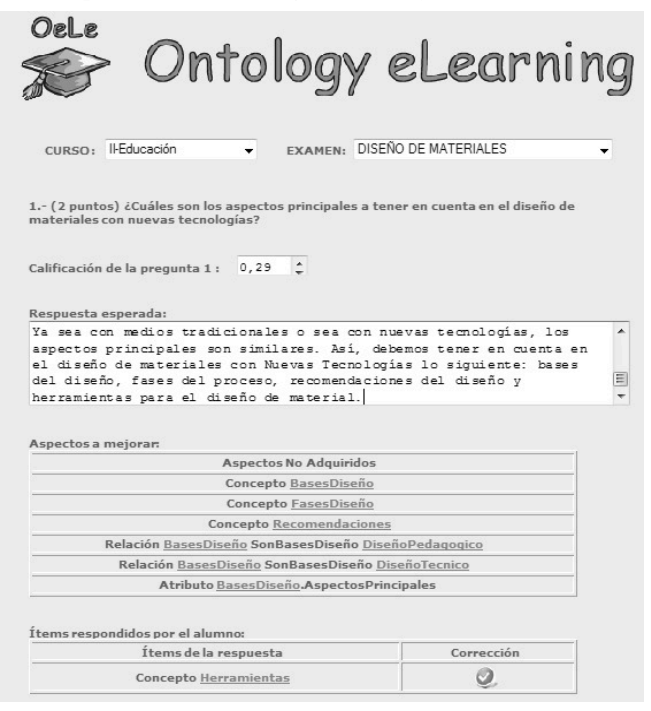

\subsection{Using OeLE in real settings}

OeLe was used during an e-Learning course at the University of Murcia. The course took place in the second semester of 2008/2009 with a group of 25 students. This subject has a practical orientation and has as its main goal to train the students in the aspects of content design, production and evaluation within the framework of didactic processes. All the work is realized in the virtual e-Learning platform at the University of Murcia: SUMA (http://suma.um.es/).

Students' academic performance was assessed with an eportfolio and other different activities throughout the 9 units in the program and also taking into account the participation of students in several communication scenarios (videoconferences and collaborative work activities). The students also had to take a written exam in a specific assessment environment. OeLE was the assessment environment used in this course, and our research was focused on this part of the course. The rest of variables defining the course were taken into account when designing, analyzing and evaluating the experience, but the attention was mainly focused on testing the educational usefulness of this innovative assessment and feedback system.

The experiment was executed as follows. Students took an exam using the OeLE platform, after which exams were assessed by OeLE, thus generating the feedback information for each student as well as for the teacher. The exams were marked by one of the course teachers too. At that stage, students were given access to reinforcement contents for one week; in other words, students had the chance to revise the contents associated with the course knowledge items that they had not answered correctly in the exam. Then, those students took a second exam which was marked exactly as the first one. Finally, the students were asked to fill in a questionnaire about the experience, which permitted to analyze the experience as a whole.

The data analysis revealed that the marks in the second exam where higher than in the first one. This is an expected result because considering that feedback was provided to students and the second exam took place only a few days later. Our analysis shows that feedback was one of the most highly assessed aspects in this experience. These results are in line with those found in previous works (e.g. Gordijn \& Nijhof, 2002; Wang \& Wu, 2008). Most students considered it positive, and a positive link was identified between the idea that feedback is useful in online 
assessment environments and the usefulness assigned to the feedback received in the experience.

The feedback generated by the platform allowed teachers to know which aspects had been acquired best and worst by students. This seemed interesting to teachers because each knowledge item has a relative importance associated to each annotation in the questions. In this experience, the best acquired concepts were those with a higher relative value.

\subsection{Methodological issues}

This experience allowed us to define the methodology for using this kind of semantic web approach to support assessment processes.

The recommendations of various authors (Noy \& McGuinness, 2001; Devedzic, 2007; Fernández et al., 2007; Horridge, 2009) should be taken into account when working with ontologies.

The program Protegé represents the best option to create the ontology. The ontology has to model the course knowledge in terms of teaching and asking, and paying attention to the way in which the contents are related. It is advisable to establish connections between concepts. Answering the following questions posed by Noy and McGuinness (2001) can help when it comes to create the ontology:

- What is the ontology domain?

— How will the ontology be used?

- What types of questions in the ontology should provide answers?

— Who will use and maintain the ontology?

In the course of the OeLE experience, different meetings were held with the subject lecturers in order to define what aspects they took into account to evaluate students' answers. Aspects such as clarity, simplicity and originality in the response (to avoid copy-paste) and provision of examples were the most outstanding. These aspects were also included in the ontology.

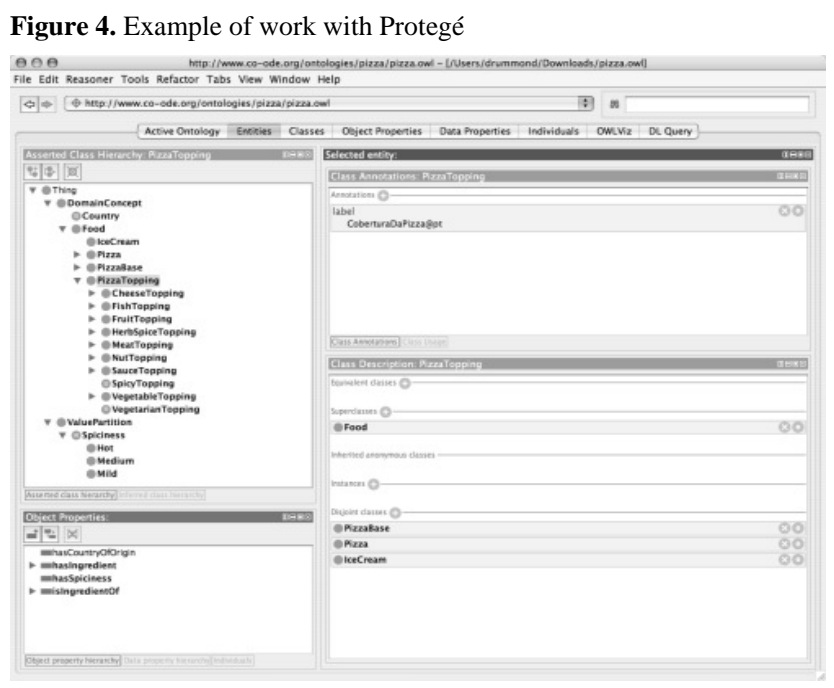

The next step is to list important terms in the ontology. For this purpose, it is useful to write a list of all the terms about which statements are going to be made or explanations are going to be given to the user. There is consequently a need to ask ourselves what the important concepts are.
The way to create the ontology is through the use of classes, sub-classes and the relationships between them. It is worth highlighting that a hierarchy will be established. The ontology refers to the exam questions, so lecturers might be tempted to organize the ontology taking the questions as their essential reference. Our advice is to create the ontology based on contents, though not on those corresponding to entire course; the prototype of answers created for our review should be the reference.

\section{DEVELOPMENT OF EDUCATIONAL SEMANTIC WEB APPLICATIONS: ENSEMBLE}

Exhibit is a tool inside the SIMILE project (Semantic Interoperability of Metadata and Information in unLike Environments). This project aims to enhance inter-operability between digital assets, schemata/vocabularies/ontologies, metadata, and services. They seek to provide end-user services by drawing upon the assets, schemata/vocabularies/ontologies, and metadata held in such stores (http://simile.mit.edu/wiki/SIMILE:About). Exhibit is a data linking/aggregation tool but it gives you some of the affordances of the semantic web without the need for ontologies. Exhibit allows you to easily create web pages with advanced text search and filtering functionalities with interactive maps, timelines, and other visualizations.

Hyun, Kragen, and Miller (2008) specify that the Semantic Web has been dismissed by many specialists because it can show an unrealistic view, since it was launched as a resource in which automated software agents can collect structured data carrying out complex tasks on behalf of users.

\subsection{The ENSEMBLE project}

Our next focus of interest is the different educational contexts and the role that ontologies can play in them. The Semantic Technologies for the improvement of problem-based learning project (ENSEMBLE) is a good example of how to work differently with the information and develop Semantic Web applications. This project directed by Patrick Carmichael stands out as one of the major international projects that studies the application of the Semantic Web in Education and does research into case-based learning and the Semantic Web.

What mainly differentiates it from other research projects on the Semantic Web is its educational perspective. It tries to analyze the implications associated with the use of Semantic Web technologies in education, while many research groups focus exclusively on technical issues. The project works with teachers, undergraduates and graduate students and tries to identify the aspects in which the Semantic Web can improve their learning as well as the role that Semantic Web technologies and techniques can play in supporting such learning.

Martínez, Morris, Tracy, and Carmichael (2011) explain how they developed several applications for different areas (plant sciences, archaeology...) through the exploration cases. The project has been developed through a wide range of semantic applications especially focused on teaching.

The dance project stands out among their many projects. Due to its context and contents, this project required the extension of frameworks for the tools with which they worked. They created a web environment containing interrelated information where students can interact with applications and information. It is a 
good example of how important resources can support description using formal vocabularies that provide a means of communication across settings and contexts (Martínez et al., 2011). Processes such as information interaction and connection can illustrate a way of applying the Semantic Web to education without ontologies. The particular benefits from semantic web technologies that they describe on the website are:

- Consistent metadata allows content to be stored and retrieved from a digital repository through web interfaces.

- Faceted browsing allows searching for collections, and as in the first demonstration below, exploration of the relationship between formal ontologies and informal, usergenerated vocabularies.

— The semantic “mark-up” of video content, linking it to parts of performances, other resources and terms.

- Annotation of contents (including video) makes it possible for students to assemble their own collections and supports the "case building" described above.

Figure 5. Dance photo viewer

(http://ensemble.ljmu.ac.uk/projects/tests/TestDance/index.html)

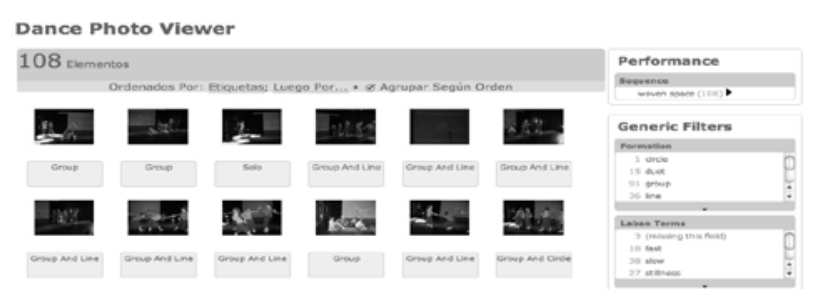

Another example is MOAM (Maritime Operations and Management), a course on maritime operations and management. This is a Master's course imparted at the City University London. In this course, students work on real cases with different practical assignments that formulate a problem to which they need to give a practical solution. The course includes several learning scenarios, for example, a task may be to design a ferry service from the islands to the coast of Cornwall (Stcholl, Tracy, \& Carmichael, 2009). Students must play the role of experts in different domains (e.g. economists, security engineers, technical designers), presenting and defending their work before a panel of experts. This way of using cases requires an approach where a reflection is made on technological support for semantic tools.

\subsection{Methodological issues}

Some supporters of a traditional Semantic Web perspective might ask where the OWL ontologies are and how we can include them in these open models. Hyun, Krag, and Miller (2008) give us the answer indicating that they have chosen a different syntax model, which is not based on RDF/XML, and also that they accept the limitations derived from not working with such languages because they can take advantage of the Exhibit work method, thanks to which faster, more practical and user-friendly applications may be developed.

For them, it is counterproductive to generate automated forms from the OWL code. In their view, the critical first step towards the generalization of the Semantic Web is to generate large amounts of data, and Exhibit is a tool that creates incentives for authors to make this happen. The rationalization of the data can come later.
The ENSEMBLE project describes how to create a semantic web application in five easy steps on its website (http://ensemble.ljmu.ac.uk/):

- Step 1: The initial spreadsheets. Work should start with a handful of basic data tables, each containing rows that detail different types of data (philosophers, sessions, readings...) linked to provide semantic associations.

- Step 2: The 'people' spreadsheet run through Babel. Working with the data is only possible after changing them from spreadsheets into a record format that your web browser can understand. The SIMILE project (home to Exhibit) hosts an online service to do exactly that: Babel. The service can also create very crude mock-up Exhibits from the spreadsheets that are fed into it. This is a useful tool for visually checking the correctness of our data before beginning to work with a full Exhibit version ourselves.

- Step 3: The 'themes' page as a skeleton Exhibit. Once the data have been obtained from Babel as JSON (JavaScript Object Notation, a data file format often used by web applications), it is possible to start building our Semantic Web site. The first step is to throw up a view and a few facets to check that our data are fit for our purposes.

- Step 4: The 'themes' page with proper lenses. After checking that the skeleton is appropriate, it can be further developed using lots of Exhibit features, like HTML lenses to control how each record is shown.

- Step 5: The final site. The great thing about semantic data is that it is possible to view them and manipulated in many different ways as long as they have plenty of solid connections to link different records. The same data sets were used on the final site over and over again to drive several learning resources, all of them created using the same Exhibit tools.

The really interesting part of the aforementioned experience is the effort made to work in trying to integrate ontologies within a context related to a specific learning. As could be seen at the beginning of this section, soft ontologies try to put together apparently irreconcilable ontological differences through a contextual analysis. This means that when an attempt is made to represent knowledge in a structured way, disciplines or domains often appear that cannot be structured by defining a clear ontology. Taxonomies related to structured knowledge combined with the utilization of other tools can help solve this problem.

One possibly appropriate way to represent information in this situation is to develop the ontology on the basis of Bloom's taxonomy. As shown above, Bloom's taxonomy represents a way to classify instructional activities or questions as they progress in difficulty. This taxonomy provides a useful structure where test questions can be categorized in the assessment of student learning. 


\section{DISCUSSION AND CONCLUSIONS}

In practice, ontologies have become widely used because they are reusable and shareable (Brewster \& O'Hara, 2007). The opportunity to work in different projects leaves us in a privileged position when analyzing both perspectives about the possibilities to work with ontologies in educational environments. The educational advantages and opportunities offered by both OeLE and MOAM experiences are explained below:

\section{OeLE:}

a) OeLE application is an innovative assessment system which has as its biggest advantage that it provides students with mechanisms to obtain information about their weaknesses. It also provides teachers with mechanisms to ensure that their students meet their individual and collective performance goals as well as to react effectively with the ultimate aim of improving student learning.

b) Building ontologies is actually a time-consuming task cost; however, creating the ontology immediately brought the advantage of obtaining an explicit categorization of the elements and relations involved in the knowledge model, so that the model could be edited, managed and reused. Moreover, the semantic organization of feedback by learning objects implies the possibility of a future interrelation of several computer systems and is a more effective to manage both students' and teachers' contents.

c) Once the ontology has been developed, it can be reused in different editions of the course and the base of semantically annotated questions can be shared with other teachers and used in different course editions.

\section{MOAM:}

a) MOAM offers the possibility of working with specific learning environments and making useful tools, thanks to which it is possible to have broader domain representations. Based on standardized elements (such as Bloom's Taxonomy) the MOAM experience allows us to create future work patterns to understand how the different elements interact in an educational context.

b) The creation of working patterns allows us to know how tasks are performed in daily practice seeking to achieve specifically fixed learning goals. It is also possible to watch the patterns that respond to higher goals.

The experience in OeLE presented here means that there are situations in which the knowledge of certain elements could be clearly structured, while an experience like MOAM or dance has as its aim to include other contextual elements (taking over the idea of soft-ontology). Therefore, different elements can be distinguished in each situation. Although an attempt was made by us to include contextual elements in the OeLE experience, content representation is completely structured from the "answer model" that the teacher provides.

The following table shows the aspects developed with regard to different items:
Table 1. Differences in different structured knowledge

\begin{tabular}{ccc}
\hline & $\begin{array}{c}\text { Well-defined } \\
\text { knowledge }\end{array}$ & Heterogeneity-knowledge \\
\hline DOMAIN & $\begin{array}{c}\text { Knowledge, e- } \\
\text { learning }\end{array}$ & $\begin{array}{c}\text { Methodology, skills, } \\
\text { outcomes }\end{array}$ \\
\hline & $\begin{array}{c}\text { Already set or } \\
\text { predefined from the } \\
\text { start, learning }\end{array}$ & $\begin{array}{c}\text { Emergent, contested and at } \\
\text { different levels and using } \\
\text { different vocabulary }\end{array}$ \\
OUTCOMES & $\begin{array}{c}\text { outcomes at the same } \\
\text { level, same } \\
\text { vocabulary }\end{array}$ & \\
\hline & Representation, & Articulation, \\
ONTOLOGY & Assessment, & Representation, \\
& Feedback & Translation \\
\hline
\end{tabular}

- Domain: The knowledge that is important in an e-learning course must be organized in OeLE. The process is methodical and tries to prioritize some concepts over others. At the same time, it is important to find the most representative word of an idea and find synonyms that can help in future for experiences with well-defined knowledge. Instead, approaches like MOAM or dance focus on trying to find how to define the skills needed to understand the operation of a course, i.e. to know what content responds to the aim sought and what skill is needed to develop it.

- Learning outcomes: The learning outcomes in a welldefined knowledge experience must be fully standardized; they need to share a common vocabulary and provide alternatives that computers can understand. At first, learning goals are at the same level and it is up to the teacher to choose the most important one. The learning goals in other contexts are recent elements operating at different levels and there is a permanent attempt to improve and learn. This strategy requires deepening into the subject, so it is basic to become familiar with the methodologies, the objectives and the assessment system. OeLE also takes into account these aspects but, for MOAM, this study of learning goals is the pillar of the future application. OeLE ontologies may be used in different subjects while MOAM is more specialized and localized.

- Ontology: An OeLE-based ontology is created through tools like Protegé and exported in OWL formats which facilitate the execution of assessment and feedback processes as well as the association with Learning Objects. With a knowledge heterogeneity experience where we should take into account learning objects or other elements, the ontology stems from a set of structured information which is translated into a computer language so that we can relate every element specific to a case. This representation is more complicated from a technical point of view but it offers a more realistic view for the teaching of science.

- Technologies: OeLE bases its goal on creating a system for evaluating courses in e-learning environments, while MOAM aims to deepen into the benefits of an educational reality and include the Semantic Web as a part of teaching.

To the best of our knowledge, none of the existing approaches had so far succeeded in supporting the assessment of open questions using a complete semantic infrastructure before OeLE. OeLE provides the academic community with a new toolassisted method for the assessment based on open questions. 
This approach shows the value of Semantic Web technologies for building e-Learning solutions.

Hence, it is worth reflecting on the benefits can be drawn from both experiences. It cannot be said that these two experiences are completely at odds, since a number of possibilities can be explored in joint future projects:

- Creation of more realistic e-learning assessment systems adapted to the context

- The combination of OeLE evaluation as a platform to search for learning goals and activities for the teaching practice.

- The creation of a complementary tool to OeLE that allows the combination of Learning Objectives with learning goals and their implementation in networked assessment environments.

There is not a single exclusive way to work with ontologies nowadays. The first step should be to analyze the type of content and context in which work is being carried out. After doing that, it is possible to work with different tools ranging from more structured and closed ontological models (with programs such as Protegé) to more open models where other tools are utilized to structure information.

There is no doubt whatsoever that something is happening at the Semantic Web. Several lines in which work could be undertaken combining both perspectives are open for the future. One of the most outstanding ones is the development of an OeLE tool including elements from soft ontologies such as MOAM works, which offer a more realistic view of the subject.

It should equally be remembered that the European Higher Education Area, as well as the reform of university degrees in progress, also seeks to change teaching methodologies by orienting them towards learner-based strategies. There is additionally a full awareness of the relevance that e-Learning has in European projects. That is why none of us can afford to miss out on this chance to study these new educational opportunities from a multidisciplinary perspective.

To conclude, it is worth highlighting that the development of this tool shows how a more complete online assessment environment can be created through the OeLE application and a networked feedback system supported on Learning Objects, thus generating an innovative working system for e-Learning courses or subjects.

\section{REFERENCES}

Alfonseca, E., \& Perez, D. (October ,2004). Automatic assessment of open ended questions with a bleu-inspired algorithm and shallow nlp. In Proceedings of Advances in Natural Language Processing, 4th International Conference, EsTAL, Alicante, Spain, pp. 25-35.

Amorín, R., Lama, M., Sánchez E., Riera, A., \& Vila, X. A. (1995). A learning design ontology based on the IMS specification. In R. Koper, C. Tattersall, \& D. Burgos (Eds.) (2005), Current State on IMS Learning Design. Proceedings of the UNFOLD/Prolearn Joint Workshop, 1, 203-225, Vlakenburg.

Avilés, K., Diaz-Kommonen, L., Laipainen, M., \& Pietarila, J. (2003). Soft Ontologies and Similarity Cluster Tools to facilitate Exploration and Discovery of Cultural Heritage Resources. IEEE Computer Society Digital Library. Czech Republic: DEXA 2003.

Berners, T., \& Hendler, J. (2001). Sicentific publishing on the Semantic Web. In Nature. doi:10.1038/35074206

Birenbaum, M., Tatsuoka, K., \& Gutvirtz, Y. (1992). Effects of response format on diagnostic assessment of scholastic achievement. Applied psychological doi:10.1177/014662169201600406
Bittencourt I., Costa E., Silva M., \& Soares, E. (2009). A computational model for developing semantic web-based educational systems.

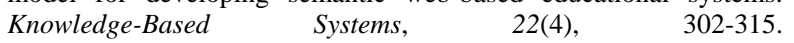
doi:10.1016/j.knosys.2009.02.012

Bloom, B. S. (1956). Taxonomy of educational objectives: the classificaction of educational goals. Handbook I, cognitive domain. Toronto: Longman.

Bouquet, P., Dona, A., Serafini, L., \& Zanobini, S. (2002). Contextualized local ontologies specification via CTXML. AAAI-02 workshop on Meaning Negociation, 28, 200-2.

Brewster, C., \& O'Hara, K., (2007). Knowledge representation with ontologies: Present challenges-future possibilities. International Journal of Human-Computer Studies, 65(7), 563-688. doi:10.1016/j.ijhcs.2007.04.003

Corcho, O., Fernández, M., \& Gómez, A. (2003). Methodologies, tools and languages for builing ontologies. Where is their meeting point?. Data and Knowledge Engineering, 46(1), 41-64. doi: 10.1016/S0169-023X(02)00195-7

Devedzic, V. (2006). Semantic Web and Education. Springer's Integrated Series in Information Systems. USA: Springer.

Devin, C. (1998). Panlingua. Retrieved from http://www.strout.net/info/science/ai/panlingua/intro.html

Falquet, G., \& Mottaz, C. (2004). Ontology based interfaces to access a library of virtual hyperbooks. In R. Heery \& L. Lyon (Eds.), ECDL, 3232, of Lecture Notes in Computer Science, pp. 99-110.

Fensel, D., Staab, S., Studer, R., van Harmelen, F., \& Davies, J., (2003). Towards the Semantic Web. In J. Wiley \& L.C. Sons. (Eds.), A Future Perspective: Exploiting Peer-to-Peer and the Semantic Web for Knowledge Management, 245-264.

Fernández, J., Prendes, M. P., Castellanos, D., Martínez, F., Valencia, R., \& Ruíz, J. (2007). Evaluación en e-learning basada en tecnologías de la Web semántica y procesamiento del lenguaje natural. Murcia: Diego Marín.

Fernández-Breis, J. T., \& Martínez-Béjar, R. (2002). A cooperative framework for integrating ontologies. International Journal HumanComputer Studies, 56(6), 665-667. doi:10.1006/ijhc.2002.1010

Friedler, S., A., \& Shneiderman, B. (2008). Enabling teachers to explore grade patterns to identify individual needs and promote fairer student assessment. Computers \& Education, 51(4), 1467-1485. doi:10.1016/j.compedu.2008.01.005

Gordijn, J., \& Nijhof, W. (2002). Effects of complex feedback on computer- assisted modular instruction. Computers and Education, 39, 183-200. doi:10.1016/S0360-1315(02)00025-8

Gruber, T. (1993). Toward principles for the design of ontologies used for knowledge sharing. In Technical Report KSL (pp. 93-104). Stanford University: Knowledge Systems Laboratory.

Horridge, M. (2009). A practical guide to building OWL Ontologies Using Protegé 4 and CO-ODE Tools. Edition 1.2. University of Manchester. Retrieved from http://owl.cs.manchester.ac.uk/tutorials/protegeowltutorial/

Huynh, D, F., Karger, D. R., \& Miller, R. C. (2008). Exhibit: Lightweight structured dada publishing. Retrieved from http://people.csail.mit.edu/dfhuynh/research/papers/www2007\%C2\%AD\%E2\%80\%90exhibit.pdf

Maicher, L., \& Park, J. (Eds.), (2005). Charting the Topic Maps Research and Applications Landscape. Springer.

Martínez, A., Morris, S., Tracy, F., \& Carmichael, P. (2011). Case Based Learning, Pedagogical Innovation and Semantic Web Technologies. IEEE transactions. Learning Technologies, 10(10).

McGrath, P. (2003). Assessing Students: Computer Simulation vs MCQs. In Proceedings of the 7 th Computer Assisted Assessment Conference.

Mitchell, T., Aldridge, N., Williamson, W., \& Broomhead, P. (2003). Computer based testing of medial knowledge. In Proceedings of the 7th Computer Assisted Assessment Conference.

Noy, N. F., \& McGuinness, D. L. (2001). Ontology development 101: a guide to creating your first ontology. Stanford Kwnoledge System Laboratory Technical Report and Stanford Medical Informative Technical Report, SMI 2001-0880. Retrieved from http://protege.stanford.edu/publications/ontology_development/ontol ogy101.pdf

Olsen, M. B. (1998). Translating english and mandarin verbs with argument structure. Tech. rep., New Mexico State University.

Palmer, K., \& Richardson, P. (2003). On-line assessment and freeresponse input: a pedagogic and technical model for squaring the circle. In Proceedings of the 7th Computer Assisted Assessment Conference. 
Stojanovic, L., Staab, S., \& Studer, R. (2001). E-Learning based on the Semantic Web. In WebNET 2001. Retrieved from http://www.aifb.uni-

karlsruhe.de/WBS/Publ/2001/WebNet_lstsstrst_2001.pdf

Tiropanis, T., Davis, H., Millard, D., WeaL, M., Wills, G., \& White, S. (2009). Linked data as a Foundation for the deployment of Semantic applications in Higher Education. In SWEL09: Ontologies and social Semantic Web for Intelligent Educational Systems AIED09 Conference. Brighton, UK.

Tscholl, M., Tracy, F., \& Carmichael, P. (2009, September). Case Methods, Pedagogical Innovation and Semantic Technologies. In 1st International Workshop on Semantic Web Applications for Learning and Teaching Support in Higher Education (SemHE'09) ECTEL'09, Nice, France. Retrieved from http://eprints.ecs.soton.ac.uk/18050/1/semhe09_submission_3.pdf

Van Heijst, G., Schereiber, A.T., \& Wielinga, B. J. (1997). Using Explicit Ontologies in KBS Development. In International Journal of Human and Computer Studies, 47.

Wang, S., \& Wu, P. (2008). The role of feedback and self-efficacy on web- based learning: The social cognitive perspective. Computers and Education, 51, 1589-1598. doi: 10.1016/j.compedu.2008.03.004

Whittingdon, D., \& Hunt, H. (1999). Approaches to the computerised assessment of free-text responses. In 3rd International Computer Assisted Assessment Conference.

\section{ACKNOWLEDGMENT}

This article is framed within the project 'Evaluation in Elearning based on Semantic Web and NLP technologies', funded by Fundación Séneca, and the 'Platform based on Semantic Web and e-Learning standards to improve selfassessment and autonomous learning in educative settings', also funded by Fundación Séneca. 